Supplement of The Cryosphere, 9, 53-64, 2015

http://www.the-cryosphere.net/9/53/2015/

doi:10.5194/tc-9-53-2015-supplement

(C) Author(s) 2015. CC Attribution 3.0 License.

(c) (i)

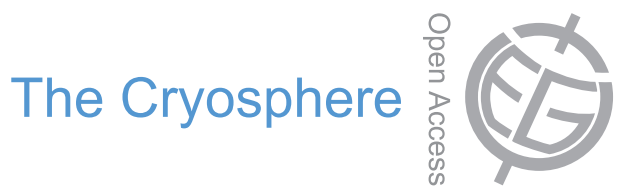

Supplement of

\title{
Recent summer Arctic atmospheric circulation anomalies in a historical perspective
}

\section{A. Belleflamme et al.}

Correspondence to: A. Belleflamme (a.belleflamme@ulg.ac.be) 


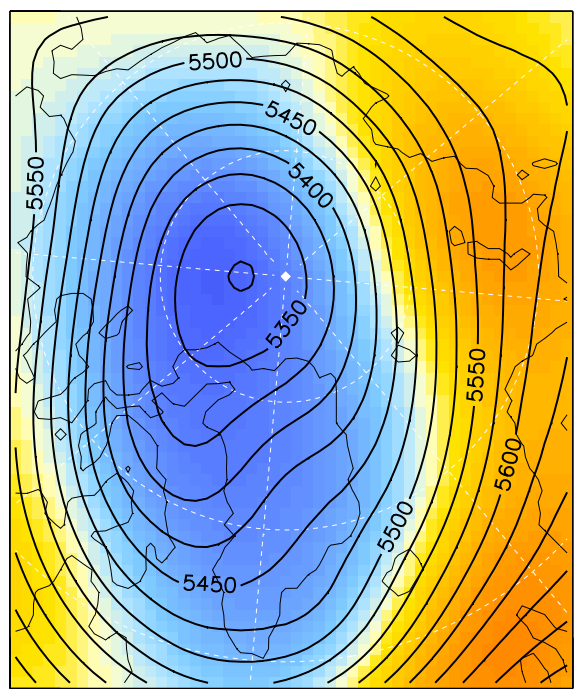

Type $\mathbb{1}-25 \%$

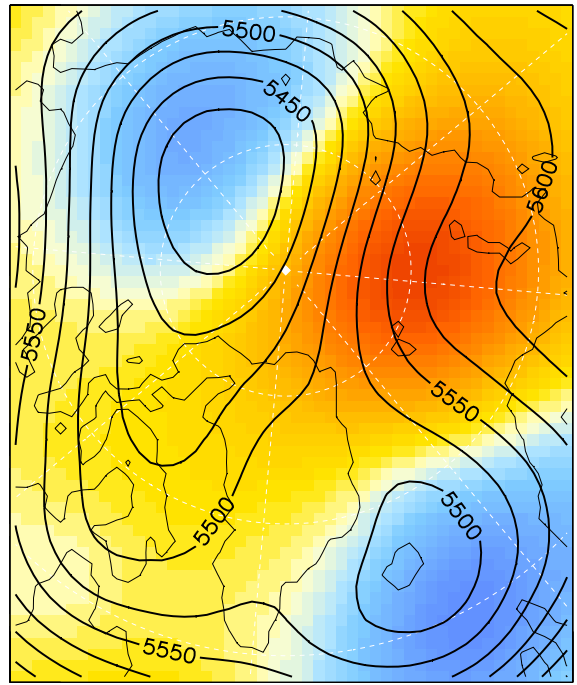

Type $4-16.6 \%$

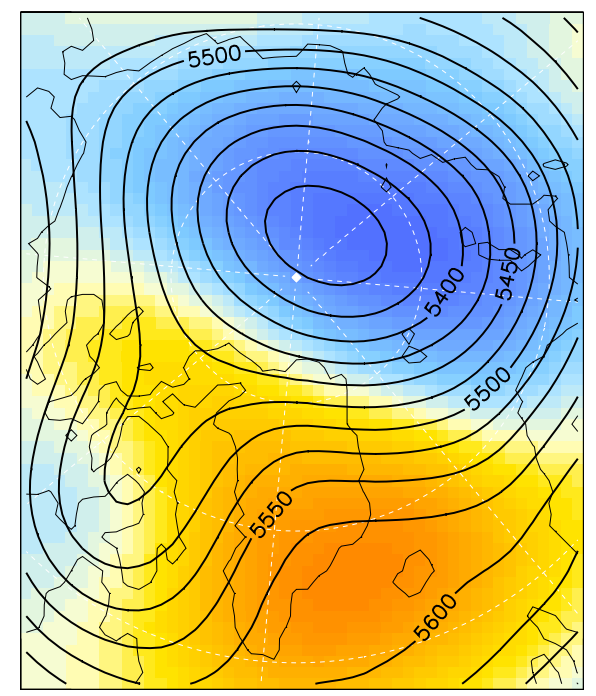

Type $2-21.3 \%$

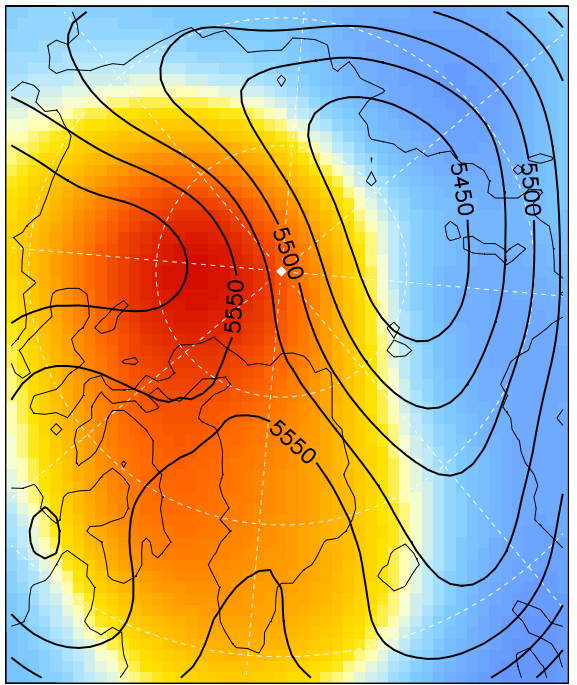

Type $5-11.3 \%$

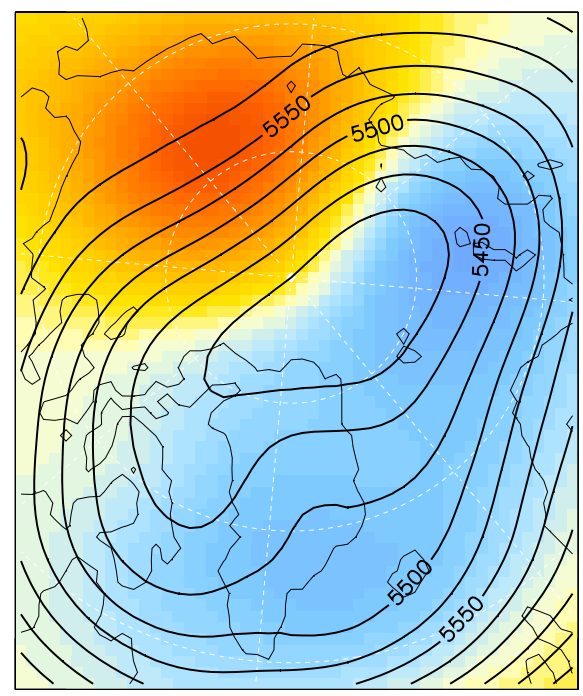

Type $3-19.6 \%$

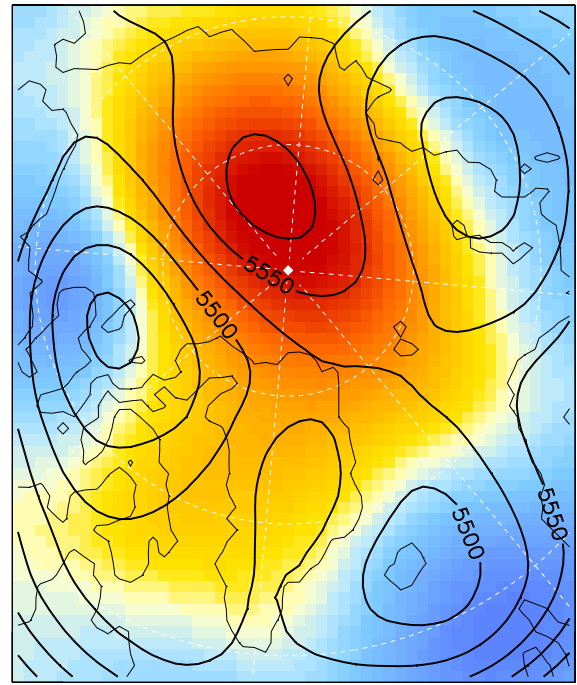

Type $6-5.9 \%$

$-150$

$-75$

0

75

150

Geopotential height at $500 \mathrm{hPa}$ anomaly (m)

Figure S1. The Z500-based reference circulation types over the 1980-2012 (JJA) period for ERA-Interim are represented by the solid black isohypses (in m). The Z500 anomaly (in colours) is calculated as the difference between the class mean Z500 and the seasonal mean Z500 over 1980-2012. The average frequency of each type is also given. 

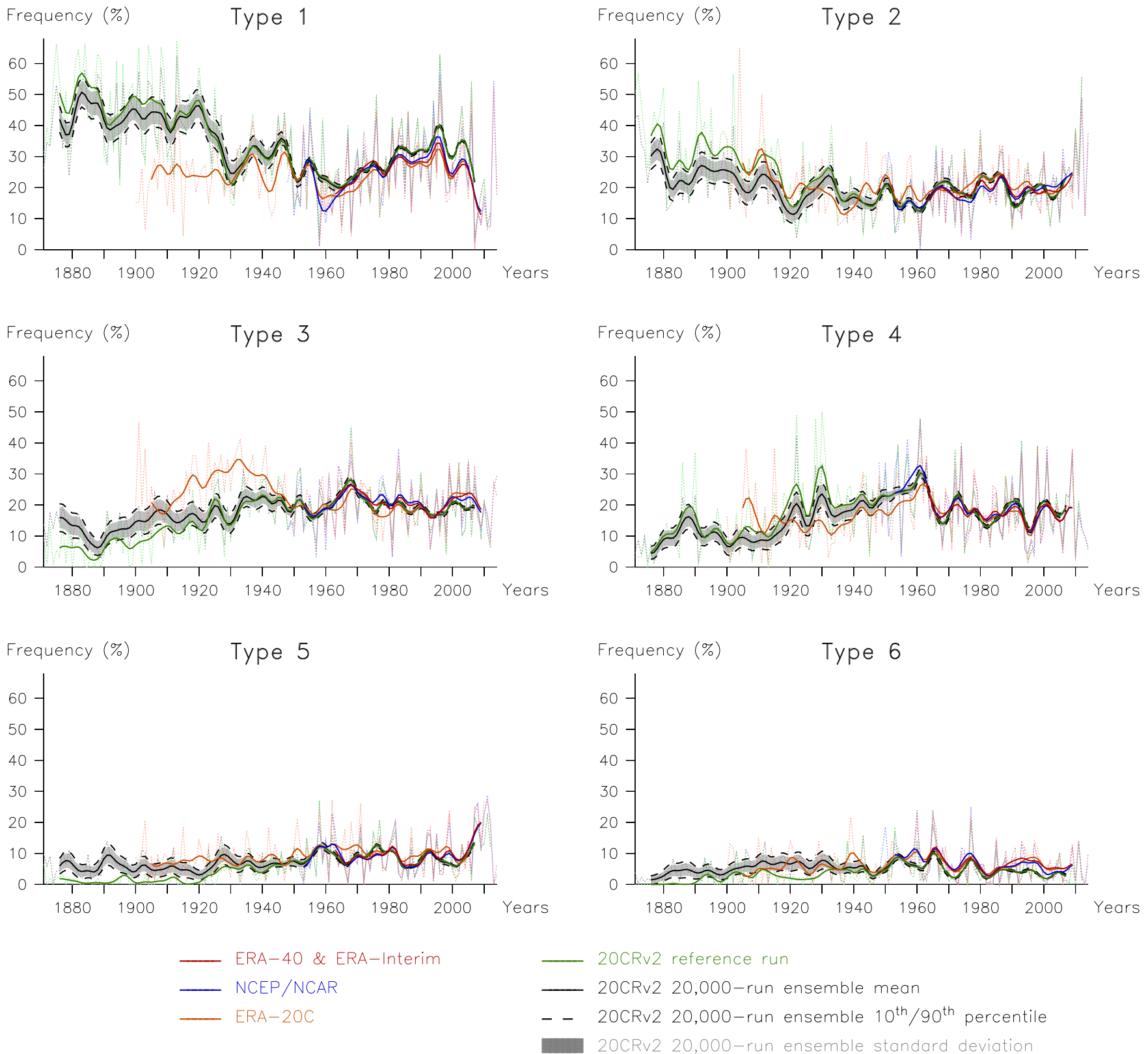

Figure S2. The dotted light lines represent the annual (JJA) Z500-based circulation type frequencies for ERA-Interim (1979-2014) and ERA40 (1958-1978), NCEP/NCAR (1948-2014), ERA-20C (1900-2010), and the 20CRv2 reference run and the 20CRv2 $20000-$ run ensemble mean (1871-2012). The corresponding solid lines represent the 10 year binomial running mean frequencies. For the $20 \mathrm{CRv} 220000-\mathrm{run}$ ensemble, the 10th and the 90th percentiles as well as the one standard deviation interval around the mean are also given. 


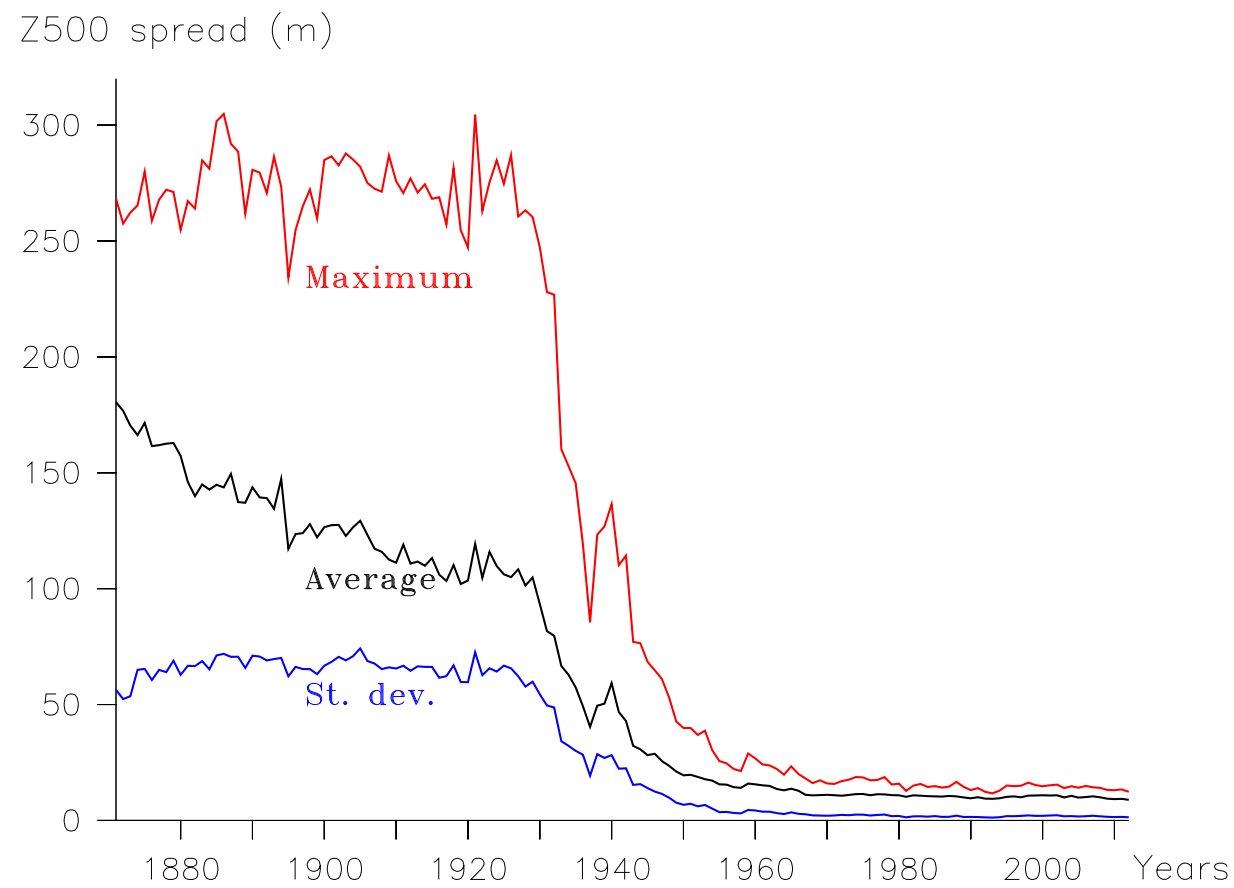

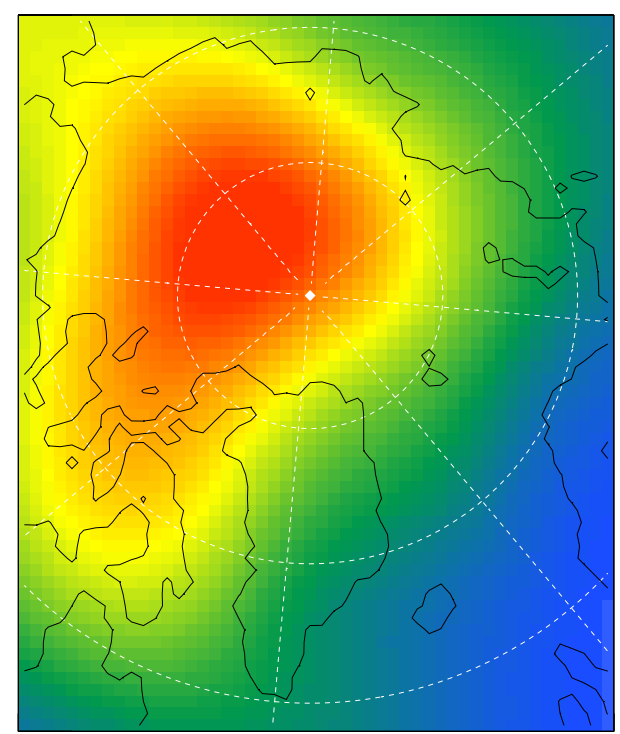

$1871-1930$

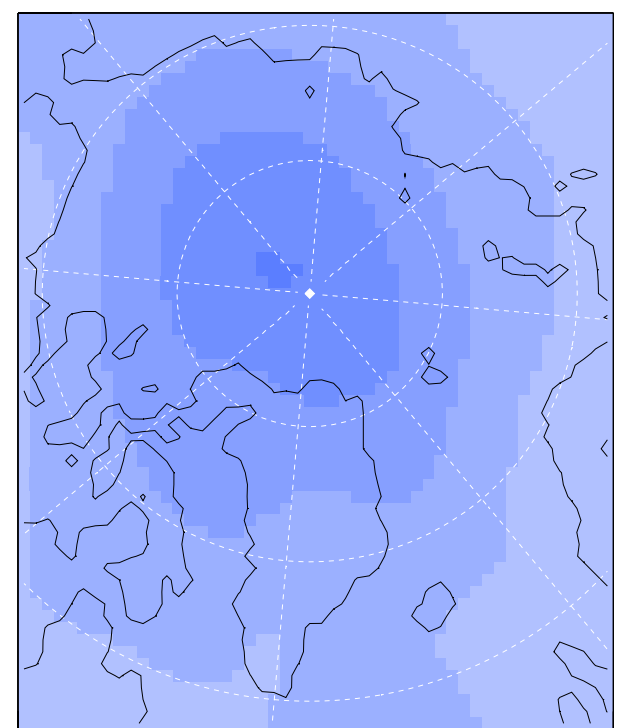

$1950-2012$

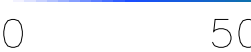

50

100

150

200

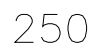

\section{Mean Z500 spread $(m)$}

Figure S3. Top: the average Z500 spread and its standard deviation are calculated as the seasonal (JJA) average $20 \mathrm{CRv} 2$ spread and its standard deviation over all pixels of our domain. The maximum Z500 spread is the value of the pixel showing the highest seasonal (JJA) average spread of each year. Bottom: the Z500 spread is calculated as the average 20CRv2 spread over the 1871-1930 summers (JJA), left, and over the 1950-2012 summers, right. 

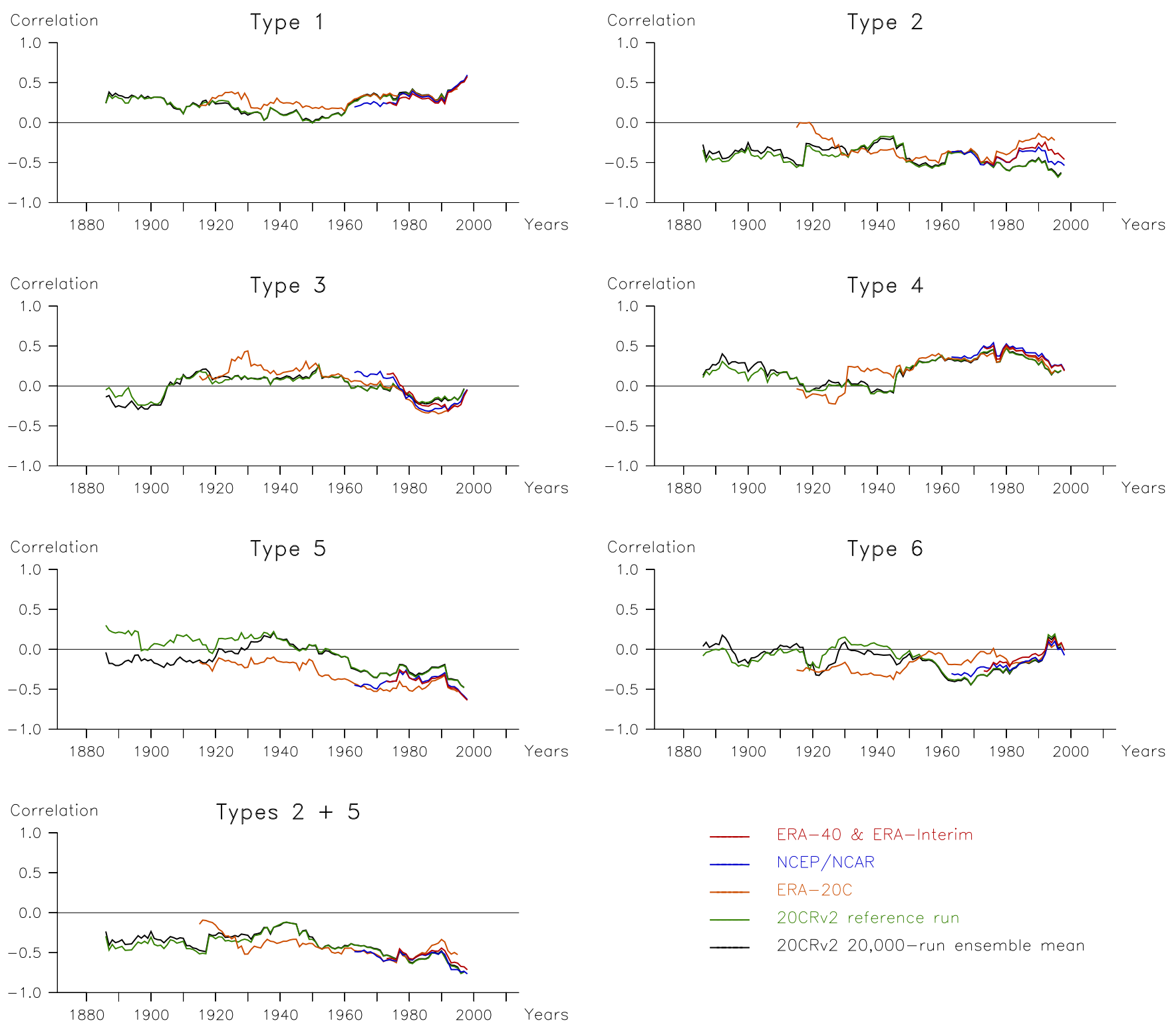

Figure S4. The 30 year running correlation is calculated between the annual (JJA) Z500-based frequencies of each type and the JJA CRU NAO index. For the "Types $2+5$ " correlation, the frequencies of Types 2 and 5 have been summed before computing the correlation. 
Table S1. For the Z500-based circulation types, which show a frequency increase over the 2007-2012 period, the summers presenting a higher frequency than the 90th percentile frequency (i.e. a 10 year return period) on the basis of the 20CRv2 reference run over 1871-2012 (JJA) are listed chronologically.

\begin{tabular}{cc}
\hline Type 2 & Type 5 \\
\hline 1871 & 1927 \\
1872 & 1954 \\
1873 & 1958 \\
1877 & 1962 \\
1879 & 1971 \\
1880 & 1975 \\
1885 & 1977 \\
1891 & 1981 \\
1895 & 1982 \\
1902 & 1992 \\
1933 & 1993 \\
1966 & 1995 \\
1980 & 2007 \\
2010 & 2008 \\
2012 & 2011 \\
\hline
\end{tabular}

